\title{
Muskingum Yönteminin Sürtünme Katsayısına (n) Bağlı Performans Analizi
}

\author{
Metin SARIGÖL1
}

\section{Özet}

Taşkın ötelenmesi, taşkın dalgasının bir kanal veya hazne boyunca herhangi bir noktadaki debi değerlerinin zamana bağlı olarak değişiminin hesaplanmasıdır. Taşkın kontrolü açısından taşkın öteleme hesaplarının pek çok faydası bulunmakta olup, bunların en önemlisi, akarsuyun belirli bir kesitteki taşkın büyüklükleri bilindiğinde, bu kesitin kilometrelerce mansabındaki bir kesitteki taşkın hidrograflarının saatlerce önceden tahmin edilebilmesi ve böylece can ve malın kurtarılması ve taşkın zararlarının azaltılması için gerekli zamanın kazanılabilmesi ve sonuçta taşkın zararlarının azaltılmasıdır. Bu çalışmada, ülkemizdeki 8 ayrı havzada yer alan 18 adet akım gözlem istasyonunun (AGI) saatlik debi verileri kullanılarak taşkın ötelenme çalışması yapılmıştır. İlk olarak taşkın tarihleri tespit edilerek her bir AGİ'dan saatlik hidrograf değerleri elde edilmiş, bu veriler ile, hidrolojik yöntemlerden Muskingum Yöntemi kullanılarak ötelenme hesapları yapılmış ve elde edilen sonuçlar ölçülmüş değerlerle karşılaştırılmıştır. Bu karşılaștırma yapılırken Ortalama Mutlak Hata (OMH), Hataların Ortalama Karekökü (HOK) ve Belirlilik Katsayısı $\left(\mathrm{R}^{2}\right)$ değerleri hesaplanmış, Muskingum Yöntemi'nin sürtünme katsayısına göre performans değişimleri incelenmiştir. Sonuçta, sürtünme katsayısı arttıkça $\mathrm{OMH}$, HOK ve R2'nin genelde değișmediği ve bu nedenle Muskingum Yönteminin performansının etkilenmediği tespit edilmiştir.

Anahtar Kelimeler: Taşkın Ötelenme, Ötelenme Yöntemleri, Muskingum

\section{Friction Coefficient (n) Dependent Performance Analysis of Muskingum Method}

\begin{abstract}
Flood routing is the calculation of the time-dependent variation of the discharge values of the flood wave at any point along a channel or reservoir. In terms of flood control, flood routing calculations have many benefits, most importantly, when flood hydrographs of a section are known, flood hydro-graphs at a downstream section be estimated for hours ago, which results in gaining time to rescue live an material and a decrease in flood damages In this study, 18 discharge observation stations Discharge Observation Station (DOS) located in 8 different basins in our country were operated flood routing using hourly flow data. First, flood dates were determined and hourly hydrograph values were obtained from each DOS. Using these data, routing calculations were made by using the Muskingum method from hydrological methods and the obtained results were compared with the measured values. The Mean Absolute Error (MAE),
\end{abstract}

1Dr. Öğr. Üyesi, Üzümlü Meslek Yüksekokulu, Erzincan Binali Yıldırım Üniversitesi, Erzincan
İlgili yazar / Corresponding author: metinsarigol@hotmail.com

Bu makaleye atıf yapmak için- To cite this article Sarıgöl, M. (2019). Muskingum Yönteminin Sürtünme Katsayısına (n) Bağlı Performans Analizi. Afet ve Risk Dergisi, 2(2), 115-127. 
Muskingum Yönteminin Sürtünme Katsayısına (n) Bağlı Performans Analizi Root Mean Square Error (RMSE), and Determinant Coefficient $\left(\mathrm{R}^{2}\right)$ values were calculated, and the Muskingum Method's performance changes with respect to the river friction coefficient was investigated. As a result,

it was found that as the friction coefficient increased, MAE, RMSE and $\mathrm{R}^{2}$ generally did not change and therefore performance of Muskingum Method was not affected.

Keywords: Flood Routing, Routing Methods, Muskingum

\section{GíRiş}

Taşkınlar, yerleşim yerleri ve tarım arazilerinin zarar görmesine, yol, köprü ve baraj gibi yapıların yıkılmasına sebep olabilir. Bu gibi zararların önlenmesi veya en aza indirilmesi için baraj, sel kapanı, sedde gibi yapılar yapılmakta, ayrıca akarsu yatağında da çeşitli düzenlemeler yapılarak gerekli önlemler alınabilmektedir. Bu tür çalıșmalara yüksek meblağda paralar harcanması, olası afetlerin meydana getireceği zararlardan çok daha ekonomik olmakta ve bu ekonomik fayda çok kısa sürede geri kazanılmaktadır.

Bir taşkın dalgası akarsu yatağı veya biriktirme haznesinden geçerek mansaba doğru ilerlerken debisinde ve hızında değişime uğramaktadır. Bu değişim, taşkın dalgasının geçtiği bölgenin fiziksel ve topoğrafik özelliklerine (suyu geri tutma) bağlı olarak değişmektedir.

$\mathrm{Bu}$ nedenle, taşkın dalgasının geçişi sırasında debi, zamanla azalmakta ve zamana göre bir miktar geciktiği için bu harekete " Taşkın Ötelenmesi" denir. Başka bir deyişle taşkın ötelenmesi, taşkın dalgasının bir kanal veya hazne boyunca herhangi bir noktadaki debi değerlerinin zamana bağlı olarak değişiminin hesaplanmasıdır (Atalay, 2008).

Taşkın kontrolü açısından taşkın ötelenme hesaplarının pek çok faydası olup, ötelenme hesapları için kullanılacak olan taşkın hidrograflarının düzgün bir şekilde elde edilmesi, bununla beraber taşkınların meydana gelme sebebinin iyi anlaşılması ve taşkını en doğru bir şekilde temsil eden matematik modellerin kurulması gerekir. Bu modeller ile yapılan çalışmalar, taşkınların hareketinin incelenmesinde çok önemli bir yere sahip olup, taşkın tahmini ve bu arada gerekli önlemlerin alınmasında hayati önem arz etmektedir.

Akarsulardaki üniform olmayan zamanla değișen akımların analizinde ise genelde iki tip yöntem kullanılır.

1. Hidrolojik Yöntemler: Sadece süreklilik denklemi kullanılır ve yapılan bazı kabullere göre belli kesitlerdeki akımın zamanla değişimi hesaplanır.

2. Hidrolik Yöntemler: Akımın süreklilik ve hareket (momentum) denklemlerini bir arada kullanmak suretiyle akarsu boyunca istenilen her noktada akımın zamanla değişimi hesaplanır (Bayazıt ve Önöz, 2008).

Hidrolojik yöntemler genelde basittir, fakat bir nehir boyunca meydana gelen taşkında ters akımların ve kabarmaların olmasından dolayı genelde iyi sonuçlar vermezler. Hidrolik yöntemlerin ise hidrolojik yöntemlere göre kurulması ve çözümü daha karışıktır. Açık kanallarda kararsız akımlar için hidrolik ötelenme yönteminin oluşturulması süreklilik denklemi ile momentum denkleminin çözümüne dayanır. Bu yöntemde taşkın dalgasının hareketini temsil eden diferansiyel denklemlerin çözümü, açık ya da kapalı sayısal metotların bilgisayarda çözümü ile yapılmaktadır. Bu denklemler 1871 yılında St. Venant tarafından bulunan analitik çözümleri olmayan kısmi diferansiyel denklemlerdir. Bu denklemlerin çözümü güç olduğundan dolayı sayısal yöntemlerden yararlanılarak çözümü yapılır (Ülke, 2001). 
Afet ve Risk Dergisi Cilt: 2 Sayı: 2, 2019 (115-127)

Hidrolojik yöntemlerle yapılan ötelenme işlemleri sonucunda bulunan pik debiler, hidrolik yöntemler ile bulunan pik debilerden daima büyüktür (Haktanır ve Özmen, 1997).

Keskin (1989), çalışmasında farklı geometrik kesitlere ve değişik uzunluklara sahip akarsularda taşkın durumu irdelemiş ve taşkın ötelenme hesapları yapmıştır. Soentoro (1991), farklı eğim ve sürtünme katsayılı açık kanallara uygulanan beş tane taşkın ötelenme yöntemlerinden en iyi yöntemi bulmak için birbirleriyle mukayese etmiștir. Keskin (1994), bağımlı değişken parametreli bir dinamik yöntem için matematik denklemleri çıkararak, bu denklemler yardımı ile akarsularda taşkın ötelenmesi problemlerini incelemiştir. Durmuş (1997), akarsu yatak şeklinin ve kesit karakteristiklerinin, akarsu boyunca sabit olmayıp değişken olmasının taşkın ötelenmesi üzerinde etkisini incelemiştir. Ülke (2003), Sütçüler Havzası'nda, 4 Kasım 1995 tarihinde meydana gelen taşkına ait piklerin matematiksel olarak modellenmesinde hidrolojik yöntemlerden biri olan Muskingum Yöntemini kullanmıştır. Singh (2004), çalışmasında açık kanallardaki akım dinamiklerinin son yıllarda önemli ölçüde geliştiği, matematik ve istatistikteki gelişmelerle birlikte, hem arazi hem de deneysel verilerin toplanarak, yeni hesaplama araçlarıyla yapılan analizlerle ilgili bilgiler vermiştir. Chagas ve Souza (2005), çalışmalarında hidrodinamik model oluşturulmuş, sayısal metodlarla da taşkın ötelenmesininin çözümünü yapmışlardır. Hidrodinamik modellerin denklemlerini daha basit hale getirerek, açık sayısal yöntemleri de kullanarak çözmüşlerdir. Al-Humoud ve Esen (2006), Muskingum Metodunun güvenilirliğinin, (K ve $\mathrm{x}$ ) parametrelerinin doğru bir șekilde tahmin edilmesine bağlı olduğunu belirlemişlerdir. Gasiorowski ve Szymkiewicz (2007), çalışmalarında kütle ve momentum denklemlerinin sadeleştirilmiş taşkın ötelenme hali olan adveksiyon ya da adveksiyon-difüzyon akım iletim denklemlerini analiz etmişlerdir. Atalay (2008), taşkın ötelenme metotlarını hidrolik ve hidrolojik metotlar olarak tek tek ele alınıp irdeledikten sonra, kinematik dalga metodu için kurulan yöntem ile Muskingum Yöntemi için elle yapılan çözümü karşılaştırmıştır. Sonuç olarak Kinematik Dalga Metodunun daha iyi ötelenme yaptığını tespit etmiştir. Akbari ve Firoozi (2010), geniş bir dikdörtgen kesitli nehir boyunca uygulanan taşkın ötelenmesi hesaplarında Saint Venant denklemlerinin sayısal olarak kapalı ve açık çözümlerini ve HEC-RAS program modelini kullanmışlardır. Elbashir (2011), İrlanda'nın Brosna Nehri'nde 1990 ve 1994 yılları arasındaki taşkınlar hidrolojik metod olan Muskingum ve Muskingum-Cunge yöntemlerini uygulayarak taşkın ötelenme çalışmasını yapmıștır. Bu yöntemlerin basitliği ve doğal kanallarda uygulanmasının yaygın olmasına rağmen, kullanımları belirli koşullar ile sinırlıdır. Yaptığı analizler sonucunda, kanal eğiminin düşük olması ve hidrografın dik bir şekilde yükselmesi nedeniyle iki yöntemde de çıkış hidrografın tespitinin başarısız olduğunu göstermiştir. Ülke ve Kaya (2012), taşkın akımının modellenmesi amacıyla Muskingum Metodu ve Kinematik Dalga Metodunu (KDM) kullanmışlardır. 4 Kasım 1995 yılında Aksu Akarsuyu'nun bir kolu olan Sütçüler Değirmendere'de meydana gelen taşkın olayını dikkate alarak, DQM sonuçlarının ölçüm hidrografı ile uyumlu olduğunu ve Muskingum yöntemi sonuçlarına göre daha iyi sonuçlar verdiğini tespit etmişlerdir. Afzali (2016), çalışmasında taşkın ötelenmede daha doğru sonuçlar alınabileceği öngörülen Lineer Muskingum Yöntemi'ne dayanan yeni bir model kullanmıștır. Muskingum parametreleri taşkın süresince klasik metot için sabit kabul edilirken, bu modelde parametrelerin taşkın sırasındaki değişimleri göz önüne alınmıştır. Lineer Muskingum Yöntemi'nin parametrelerini tahmin ederken MHBMO (Modified Honey Bee Mating Optimization) algoritmasını kullanmış ve bu algoritmayı kullanarak önerdiği modeli, başka tekniklerle kalibre ederek, sabit parametreli model ile karşılaştırmıştır. Sonuçta, bu yeni modelin hatayı sadece \%50 azaltmakla kalmayıp, aynı zamanda MHBMO algoritmasının da Muskingum Yöntemi'nin parametrelerinin tahmininde rahatlıkla kullanılabileceği tespit edilmiștir. Balamurugan ve Bhallamudi (2017), çalışmalarında bileşik kesitlere sahip belli zamanlarda akım olan bir kanalda taşkın ötelenme için yeni bir yaklaşım açıklamışlardır. Önerilen matematiksel modelde, yüzey akışında Saint-Venant denklemlerinin sayısal çözümünü ve yüzey altı akışında bir boyutlu Richards denkleminin sayısal çözümünü iteratif bir şekilde yapmışlar, ana yatak ve taşkın yatağı etkileşimlerini modellemek için son zamanlarda geliştirilen etkileşimli bölünmüş 
Muskingum Yönteminin Sürtünme Katsayısına (n) Bağlı Performans Analizi kanal IDC (Interactive Divided Channel) yöntemini kullanmışlardır. Burada bir boyutlu yüzey ve iki boyutlu yüzeyaltı 1DSP2DSS (One-Dimensional Surface and Pseudo Two-Dimensional Subsurface) modelini kullanmışlar, kesitin sızma oranındaki yanal değişimin etkisinin, akımın derinliğindeki yanal değişime ve topraktaki yanal değişime bağlı olarak arttığını belirlemişlerdir. Önerilen modelin sonuçlarını literatürde mevcut olanlar ile karşılaştırarak doğru olduğunu teyit etmişlerdir. Sonuçta taşkın yatakları ve sızma oranındaki yanal değişimin etkisinde bulunan kanallarda taşkın ötelenme modelini başarılı bir şekilde uygulamışlardır. Niazkar ve Afzali (2017), değişken parametreleri olan on dört yeni Muskingum modeli önermişlerdir. Bu modellerde, öteleme süresini iki veya üç alt süreye ayırmışlardır. Böylece erişim özelliklerini daha iyi yakalamak ve öteleme sonuçlarını iyileştirmek için Muskingum Yöntemini geliştirmişlerdir. Seçilen veri setinin taşkın öteleme sonuçları, üç değişkenli parametre modelinin, üç sabit parametreli modele göre kıyaslandığında, SSQ (Sum of the Square of the Deviations) değerini \% 89'dan daha fazla azalttı̆̆ını belirlemişlerdir.

\section{2. ÇALIŞMANIN AMACI}

$\mathrm{Bu}$ çalışmada varılması hedeflenen en önemli amaç, bir taşkın afeti esnasında taşkının meydana geldiği yerdeki taşkın hidrografı kullanılarak, bu noktanın kilometrelerce mansabındaki bir yerdeki taşkın hidrografının saatlerce hatta günlerce önce tahmin edilmesidir. Böylece, can ve malın kurtarılması ve korunması için gerekli zaman kazanılır ve bu şekilde taşkın zararları en aza indirilir.

\section{YÖNTEM}

\subsection{Muskingum Metodu}

Muskingum Yöntemi 1930’lu yıllardan itibaren nehir mühendisliği uygulamalarında geniş bir şekilde kullanılmıştır (Kundzewicz ve Strupczewski, 1982).

Bu yöntem hidrolojik yöntemlerden olup, ilk olarak 1938 yılında U.S Army Corps of Engineers ve McCarty tarafından Muskingum nehrindeki taşkınların ötelenme çalışmalarında kullanılırken geliştirilen yöntem geniş bir kulanım alanına sahip olup, akarsu ötelenme işlemlerinde çok sık kullanılır. Yöntem kurulurken süreklilik denklemi baz alınır ve dinamik etkiler ihmal edilir. Bu yöntemin temeli akarsu parçasındaki hem süreklilik hem de depolama ve giriş, çıkış akımları arasında lineer bir ilişki olduğu kabulüne dayanır (Chaudhry, 2008).

Ele alınan akarsu parçasında giriş ve çıkış enkesitlerine ait hidrografların arasındaki fark, o anki hacimdeki değişimin miktarına eşittir. Bu da;

$$
x-y=\frac{d S}{d t}
$$

süreklilik denklemi ile elde edilir. Bu denklem Muskingum Yöntemi'nin temelini oluşturur. Bu süreklilik denklemi sonlu farklar metodu ile yazıldı̆̆ında;

$$
\frac{x_{1}+x_{2}}{2}-\frac{y_{1}+y_{2}}{2}=\frac{S_{2}-S_{1}}{\Delta t}
$$


Afet ve Risk Dergisi Cilt: 2 Sayı: 2, 2019 (115-127)

Metin SARIGÖL

denklemi elde edilir. Bu denklemde, $\Delta$ t zaman aralığının başlangıcında $\mathrm{x}_{1}$ : giren debi, $\mathrm{y}_{1}$ : çıkan debi $\mathrm{S}_{1}$ : depolanmış hacmi, $\Delta \mathrm{t}$ zaman aralığının sonunda ise $\mathrm{x}_{2}$ : giren debi, $\mathrm{y}_{2}$ : çıkan debi, $\mathrm{S}_{2}$ : depolanmış hacmi gösterir.

Akarsu parçasında biriken hacim, giren ve çıkan debilere bağlı olup, Muskingum Yöntemi için lineer ilişki;

$S=K[a \cdot x+(1-a) y]$

denklemi olarak kabul edilir (Chow, 1959). Bu denklemde yer alan K: Akarsu parçasından geçiş süresi sabiti, a: ağırlık faktörü olarak adlandırılır.

Muskingum Yönteminin hesap adımlarında, ilk olarak iki nokta arasındaki giriş ve çıkış hidrograflardan $\mathrm{K}$ ve a parametreleri tahmin edilir. Böylece giriş, çıkış ve depolama arasındaki lineer ilişki tespit edilmiş olur ve ötelenme işlemi yapılarak sonuca gidilir.

$\mathrm{K}$ ve a katsayılarını hesap ederken en temel yollardan biri, a' ya $0 \leq \mathrm{a} \leq 0.5$ olarak değerler verip, bu değerler sonucunda hesap edilen $(a x+(1-a) y)$ ifadesi ve S arasındaki ilişkiyi grafik olarak çizmektir. Çeşitli a katsayısına göre çizilen grafiklerden doğruya en yakın olan grafik aranılan a katsayısını, bu grafikten elde edilen doğrunun eğimi ise K değerini vermektedir.

K ve a parametrelerinin tahmininde Gill (1978), Stephenson, (1979) en küçük kareler ve lineer programlama metodu, Kshirsagar vd. (1995) doğrusal olmayan (ardışık kuadratik) bir programlama algoritması kullanmıştır.

Muskingum Yöntemi az eğimden dik eğime doğru artan eğimlerde iyi sonuçlar vermekte ve yaygın olarak kullanılmaktadır (Maidment, 1993).

Muskingum Yönteminin taban eğiminin yüksek olduğu akarsularda ve hidrografın yükselme süresinin büyük olması durumunda iyi sonuç verdiği belirlenmiştir (Ülke, 2001). Bu yöntem basitliği sebebiyle en sık kullanılan ötelenme yöntemlerinden birisidir (Tung, 1985).

\section{2. Çalışmada Kullanılan Veriler}

Çalışmada kullanılan AGİ'lerin bazı özellikleri Tablo 1'de sunulmuştur.

Tablo 1. Akım Gözlem İstasyonları ve Özellikleri

\begin{tabular}{|c|c|c|c|c|}
\hline İstasyon No & Taşkın Tarihi & Pürüzlülük (n) & Ĕğim $\left(S_{0}\right)$ & Mesafe (m) \\
\hline$\frac{1}{2}$ & 27.06.2015 & 0.087 & 0.014 & 5,044 \\
\hline 3 & \multirow{2}{*}{ 05.05.2014 } & \multirow[t]{2}{*}{0.073} & \multirow{2}{*}{0.024} & \multirow[t]{2}{*}{2,061} \\
\hline 4 & & & & \\
\hline 5 & \multirow[t]{2}{*}{05.03 .2004} & \multirow[t]{2}{*}{0.095} & \multirow[t]{2}{*}{0.0132} & \multirow[t]{2}{*}{10,000} \\
\hline 6 & & & & \\
\hline 7 & \multirow[t]{2}{*}{07.06 .2014} & \multirow[t]{2}{*}{0.053} & \multirow[t]{2}{*}{0.014} & \multirow[t]{2}{*}{1,355} \\
\hline 8 & & & & \\
\hline 9 & \multirow{2}{*}{ 28.03.2015 } & \multirow{2}{*}{0.082} & \multirow{2}{*}{0.037} & \multirow[t]{2}{*}{25,720} \\
\hline 10 & & & & \\
\hline 11 & \multirow[t]{2}{*}{06.06 .2015} & \multirow[t]{2}{*}{0.055} & \multirow[t]{2}{*}{0.01} & \multirow[t]{2}{*}{8,711} \\
\hline 12 & & & & \\
\hline 13 & \multirow[t]{2}{*}{04.04 .2014} & \multirow[t]{2}{*}{0.096} & \multirow[t]{2}{*}{0.018} & \multirow[t]{2}{*}{20,077} \\
\hline 14 & & & & \\
\hline 15 & \multirow[t]{2}{*}{04.11 .1995} & \multirow[t]{2}{*}{0.035} & \multirow[t]{2}{*}{0.028} & \multirow[t]{2}{*}{6,353} \\
\hline 16 & & & & \\
\hline 17 & \multirow[t]{2}{*}{ 20.03.2011 } & \multirow[t]{2}{*}{0.036} & \multirow[t]{2}{*}{0.028} & \multirow[t]{2}{*}{8,206} \\
\hline 18 & & & & \\
\hline
\end{tabular}


Muskingum Yönteminin Sürtünme Katsayısına (n) Bağlı Performans Analizi Taşkın Ötelenmesinde kullanılmış saatlik veriler D.S.İ (Devlet Su İşleri ) Genel Müdürlüğü Etüd Planlama ve Tahsisler Daire Başkanlığı Rasatlar Şube Müdürlüğü ve AGİ'nin bağlı bulunduğu ilgili bölge müdürlüklerinden, Sütçüler ve Selimler AGİ verileri Ülke (2003) yüksek lisans tezinden, Narağacı ve Ortakonuş AGİ verileri Özdoğan (2010) doktora tezinden alınmıştır.

İlk olarak, seçilen bölgelerde taşkının meydana geldiği zaman aralığı belirlenmiş ve DSİ'den saatlik taşkın verileri, istasyonların bulunduğu yerdeki kesit alanı ve hız değerleri temin edilmiştir. Sonuçta, çalışma kapsamındaki 18 adet AGİ istasyonun saatlik debileri $(\mathrm{m} 3 / \mathrm{sn})$ kullanılmıştır.

Taşkın ötelenme yöntemlerinde kullanılan istasyonlara ait eğim ve iki istasyon arasındaki uzaklık için DSİnin online internet sayfasından faydalanılmış (URL 2), istasyonların bulunduğu yerdeki kotlardan eğim, koordinatlarından ise mesafeler hesaplanmış ve Tablo 2.2'de gösterilmiştir.

AGİ'na ait pürüzlülük katsayıları, n’e (pürüzlülük katsayısı) değer verilerek taşkın sırasındaki seviyelere karşı gelen debi ve Manning formülü kullanılarak hesaplanan debi arasındaki farkı minimum yapan n olarak alınmıştır.

\section{3. Çalışma Alanı}

Çalışma bölgesi ilk olarak taşkınların yaşandığı Türkiye geneli olarak düşünülmüş ancak aynı akarsu üzerinde bir çok yerde iki adet Akım Gözlem İstasyonu olmadığından ve bir kısmında taşkının yaşandığı saatlerde ölçüm alınamadığından dolayı 8 havzada yer alan 9 bölgede, 18 adet Akım Gözlem İstasyonu (AGİ) belirlenmiştir. Bu AGİ'larının haritası Şekil 1'de, bazı özellikleri ise Tablo 1'de gösterilmiştir.

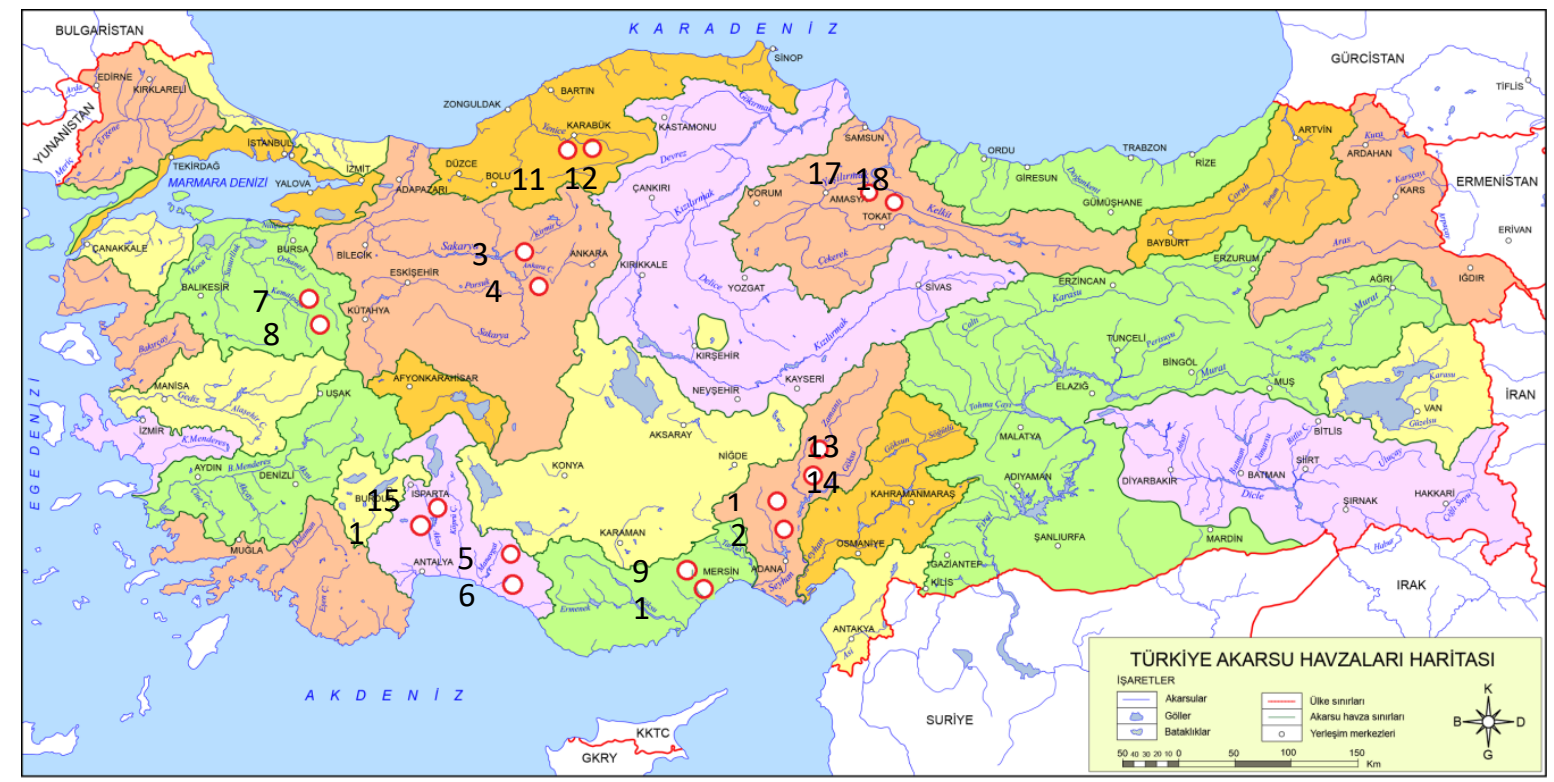

Şekil 1. Çalışma alanı (URL 1)

\subsection{Metot}

Türkiye genelinde belirlenen 9 bölgedeki 18 AGI'den edilen taşkın hidrograf verileri Muskingum Taşkın Ötelenme Yöntemi ile hesapları yapılmış ve gerçek değerler ile karşılaştırılarak hata analizleri yapılmıștır. Buna göre giriş, çıkış ve hesap hidrograf grafikleri çizilmiş ve durum analizi yapılmıştır. 


\section{BULGULAR}

\subsection{Adana Karaisalı Taşkın Ötelenme Bulguları}

Belirlenen 9 bölgede kullanılan Muskingum Ötelenme yöntemine göre yapılan hesaplar Tablo 210 'da sunulmuştur.

Tablo 2. Adana Karaisalı Muskingum Yöntemine ait Hesap Parametreleri

\begin{tabular}{|c|c|c|c|c|}
\hline \multicolumn{5}{|c|}{ Parametreler } \\
\hline $\mathrm{K}(\mathrm{sa})$ & $\mathrm{a}$ & $\mathrm{C}_{0}$ & $\mathrm{C}_{1}$ & $\mathrm{C}_{2}$ \\
\hline 0.72 & 0.48 & -0.1579 & 0.9616 & 0.1963 \\
\hline
\end{tabular}

Tablo 3. Ankara Kızılcahamam Muskingum Yöntemine ait Hesap Parametreleri

\begin{tabular}{|c|c|c|c|c|}
\hline \multicolumn{5}{|c|}{ Parametreler } \\
\hline $\mathrm{K}(\mathrm{sa})$ & $\mathrm{a}$ & $\mathrm{C}_{0}$ & $\mathrm{C}_{1}$ & $\mathrm{C}_{2}$ \\
\hline 1.11 & 0.50 & -0.5485 & 1 & 0.5485 \\
\hline
\end{tabular}

Tablo 4. Antalya Manavgat Muskingum Yöntemine ait Hesap Parametreleri

\begin{tabular}{|c|c|c|c|c|}
\hline \multicolumn{5}{|c|}{ Parametreler } \\
\hline $\mathrm{K}(\mathrm{sa})$ & $\mathrm{a}$ & $\mathrm{C}_{0}$ & $\mathrm{C}_{1}$ & $\mathrm{C}_{2}$ \\
\hline 0.48 & 0.076 & 0.2799 & 0.3899 & 0.3302 \\
\hline
\end{tabular}

Tablo 5. Bursa Harmancık Muskingum Yöntemine ait Hesap Parametreleri

\begin{tabular}{|c|c|c|c|c|}
\hline \multicolumn{5}{|c|}{ Parametreler } \\
\hline $\mathrm{K}(\mathrm{sa})$ & $\mathrm{a}$ & $\mathrm{C}_{0}$ & $\mathrm{C}_{1}$ & $\mathrm{C}_{2}$ \\
\hline 1.05 & 0.36 & 0.0970 & 0.7630 & 0.1400 \\
\hline
\end{tabular}

Tablo 6. İçel Silifke Muskingum Yöntemine ait Hesap Parametreleri

\begin{tabular}{|c|c|c|c|c|}
\hline \multicolumn{5}{|c|}{ Parametreler } \\
\hline $\mathrm{K}(\mathrm{sa})$ & $\mathrm{a}$ & $\mathrm{C}_{0}$ & $\mathrm{C}_{1}$ & $\mathrm{C}_{2}$ \\
\hline 7.11 & 0.19 & -0.1367 & 0.2965 & 0.8402 \\
\hline
\end{tabular}

Tablo 7. Karabük Safranbolu Muskingum Yöntemine ait Hesap Parametreleri

\begin{tabular}{|c|c|c|c|c|}
\hline \multicolumn{5}{|c|}{ Parametreler } \\
\hline $\mathrm{K}(\mathrm{sa})$ & $\mathrm{a}$ & $\mathrm{C}_{0}$ & $\mathrm{C}_{1}$ & $\mathrm{C}_{2}$ \\
\hline 4.09 & 0.08 & 0.039 & 0.195 & 0.766 \\
\hline
\end{tabular}

Tablo 8. Kayseri Yahyalı Muskingum Yöntemine ait Hesap Parametreleri

\begin{tabular}{|c|c|c|c|c|}
\hline \multicolumn{5}{|c|}{ Parametreler } \\
\hline $\mathrm{K}(\mathrm{sa})$ & $\mathrm{a}$ & $\mathrm{C}_{0}$ & $\mathrm{C}_{1}$ & $\mathrm{C}_{2}$ \\
\hline 2.97 & 0.34 & -0.207 & 0.613 & 0.594 \\
\hline
\end{tabular}

Tablo 9. Isparta Sütçüler Muskingum Yöntemine ait Hesap Parametreleri

\begin{tabular}{|c|c|c|c|c|}
\hline \multicolumn{5}{|c|}{ Parametreler } \\
\hline $\mathrm{K}(\mathrm{sa})$ & $\mathrm{a}$ & $\mathrm{C}_{0}$ & $\mathrm{C}_{1}$ & $\mathrm{C}_{2}$ \\
\hline 1.1 & 0.27 & 0.156 & 0.612 & 0.232 \\
\hline
\end{tabular}


Tablo 10. Tokat Merkez Muskingum Yöntemine ait Hesap Parametreleri

\begin{tabular}{|c|c|c|c|c|}
\hline \multicolumn{5}{|c|}{ Parametreler } \\
\hline $\mathrm{K}(\mathrm{sa})$ & $\mathrm{a}$ & $\mathrm{C}_{0}$ & $\mathrm{C}_{1}$ & $\mathrm{C}_{2}$ \\
\hline 0.82 & 0.50 & 0.097 & 1 & -0.097 \\
\hline
\end{tabular}

\section{2. İRDELEME}

İncelenen bölgelerdeki gözlenen ve Muskingum Yöntemine göre hesaplanan taşkın hidrografları Şekil 2-Șekil 10' da, yapılan taşkın ötelenme hesapları sonucunda hesaplanan değerlerle gerçek değerler arasındaki Ortalama Mutlak Hata $(\mathrm{OMH})$, Hataların Ortalama Karekökü (HOK) ve Belirlilik Katsayısı ( $\mathrm{R}^{2}$ ) değerleri Tablo 12-14'de gösterilmiştir.

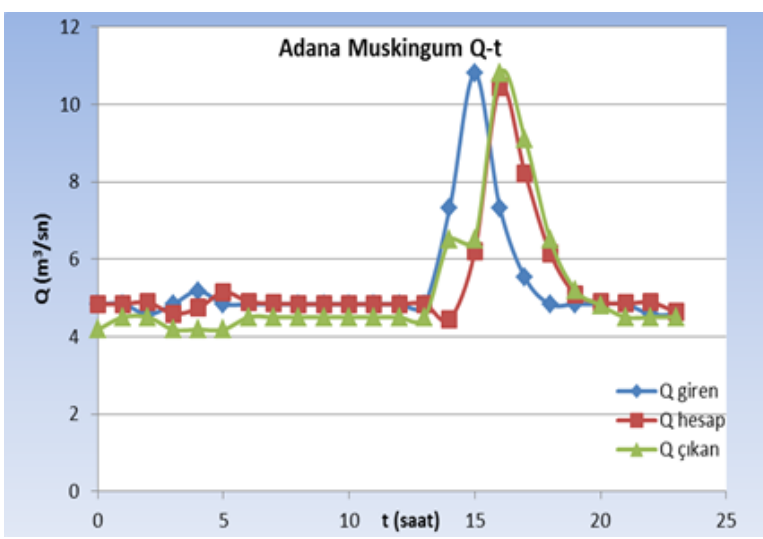

Şekil 2. 1 nolu AGİ'nin Muskingum Yöntemine göre hesaplanmış ve ölçülmüş değerleri

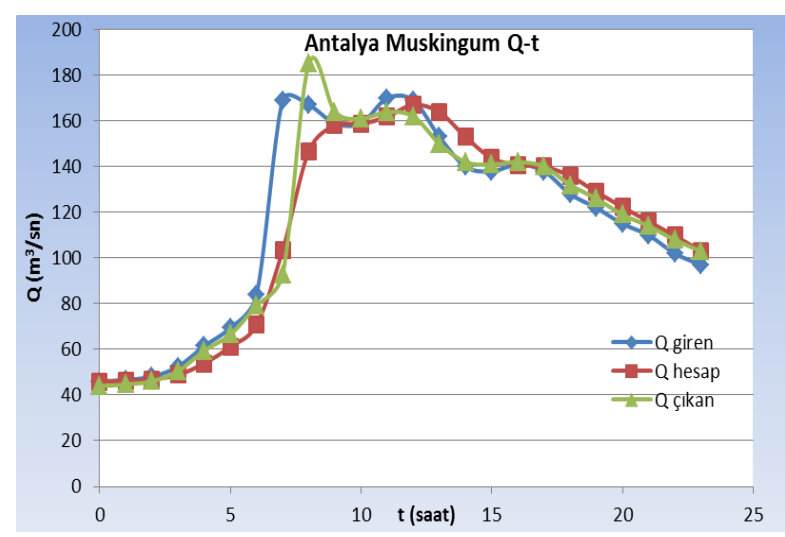

Şekil 4. 5 nolu AGİnin Muskingum Yöntemine göre hesaplanmış ve ölçülmüş değerleri

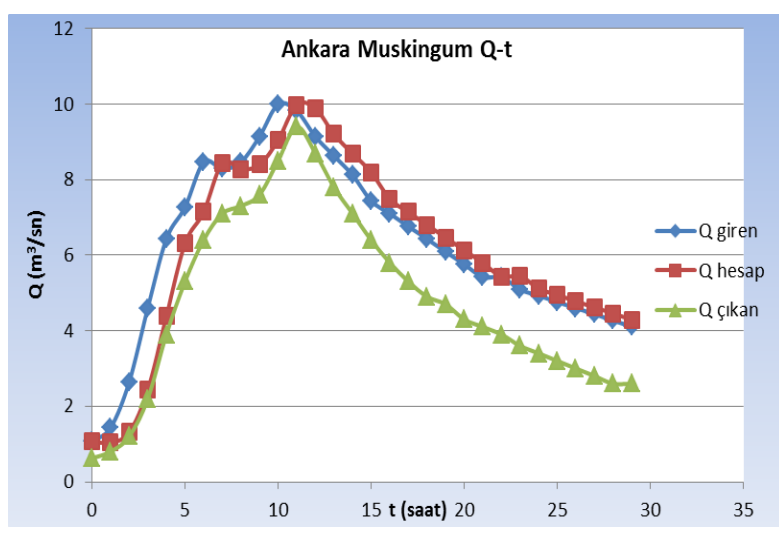

Şekil 3. 3 nolu AGİ'nin Muskingum Yöntemine göre hesaplanmış ve ölçülmüş değerleri

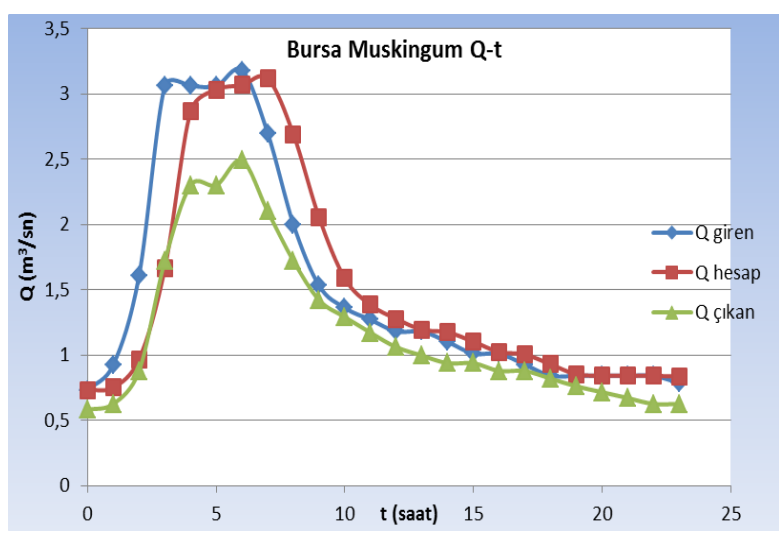

Şekil 5. 7 nolu AGİnin Muskingum Yöntemine göre hesaplanmış ve ölçülmüş değerleri 


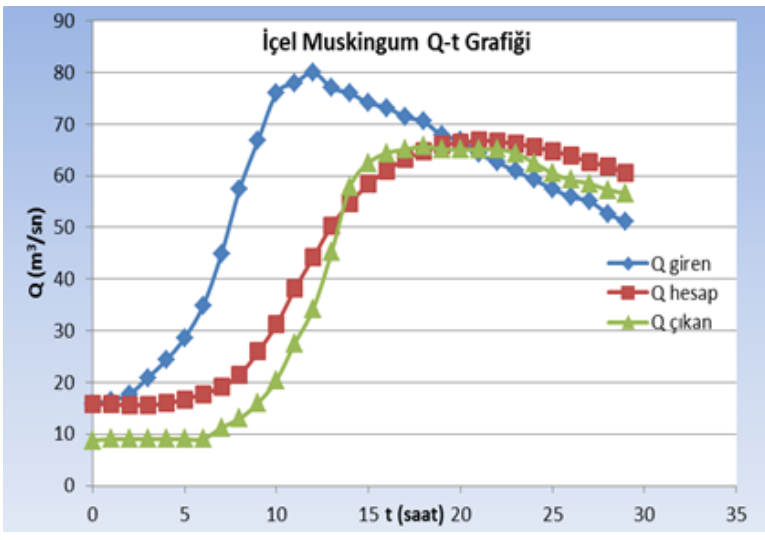

Şekil 6. 9 nolu AGİ'nin Muskingum Yöntemine göre hesaplanmış ve ölçülmüş değerleri

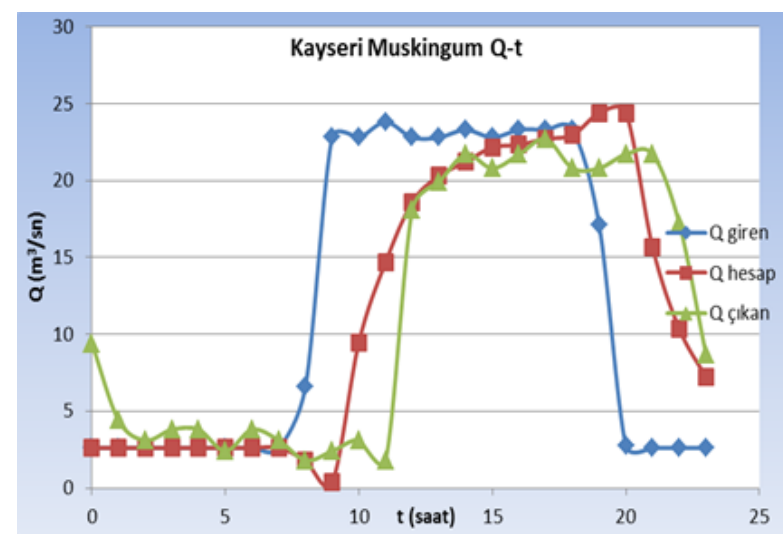

Şekil 8.13 nolu AGI'nin Muskingum Yöntemine göre hesaplanmış ve ölçülmüş değerleri

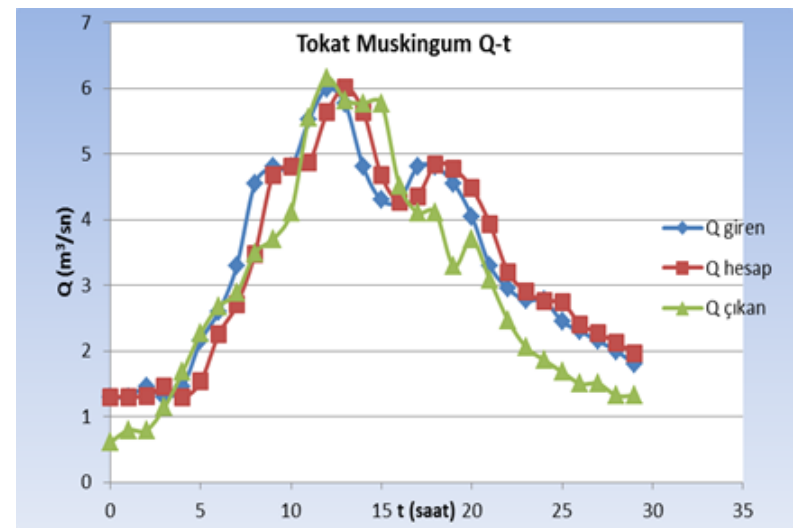

Şekil 10.17 nolu AGİ'nin Muskingum Yöntemine göre hesaplanmış ve ölçülmüş değerleri

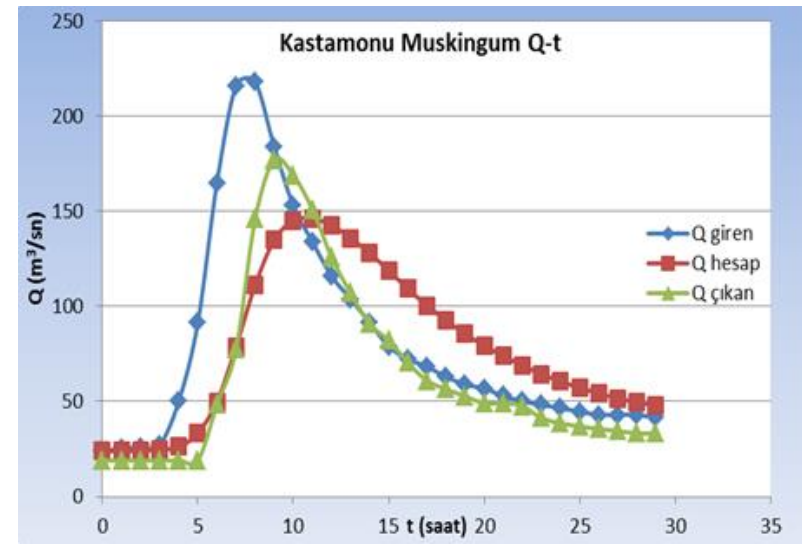

Şekil 7. 11 nolu AGI'nin Muskingum Yöntemine hesaplanmış ve ölçülmüş değerleri

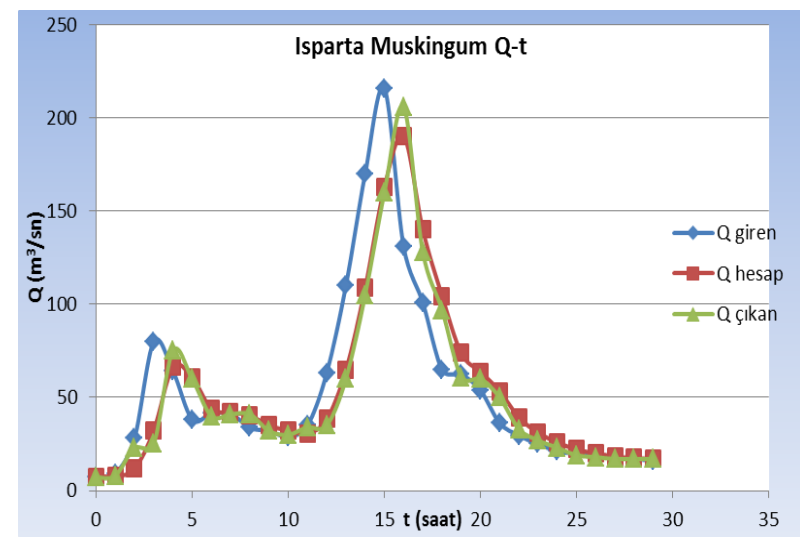

Şekil 9. 15 nolu AGİ'nin Muskingum Yöntemine göre hesaplanmış ve ölçülmüş değerleri 
Yapılan çalışmada sürtünme katsayısı $0.025-0.1$ aralığında, bunların gruplandırılması Tablo 11 'de, yapılan irdeleme sonuçları ise Tablo 12 -14'de gösterilmiştir.

Tablo 11. Çalışılan Bölgelerdeki Pürüzlülük Katsayılarının Gruplandırılması

\begin{tabular}{|c|c|c|}
\hline \multicolumn{3}{|c|}{ So Çalıșma Aralı̆̆ı } \\
\hline $0.025 \leq \mathrm{n} \leq 0.049$ & $0.050 \leq \mathrm{n} \leq 0.075$ & $0.076 \leq \mathrm{n} \leq 0.1$ \\
\hline Küçük Pürüzlülük & Orta Pürüzlülük & Büyük Pürüzlülük \\
\hline
\end{tabular}

\subsection{Muskingum Yöntemi ile Yapılan Taşkın Ötelenme Çalışma Sonuçları}

Tablo 12. sonuçları irdelendiğinde aşağıdaki tespitler yapılmıştır:

* Pürüzlülüğe bağlı irdeleme: Ortalama değerler göz önüne alındığında OMH'nin 2.53 değeri ile küçük pürüzlü akarsularda en düşük, 3.45 değeri ile büyük pürüzlü akarsularda daha büyük ve 7.49 değeri ile büyük pürüzlü akarsularda OMH'nin en büyük olduğu belirlenmiștir.

Tablo 12. Muskingum Yöntemine Göre Pürüzlülüğe Bağlı OMH Analizi

\begin{tabular}{|c|c|c|c|c|c|c|c|c|c|}
\hline \multirow{4}{*}{$\mathrm{n}$ (Pürüzlülük) } & \multicolumn{3}{|c|}{$\begin{array}{c}(0,025-0,049) \\
\text { (Küçük ) }\end{array}$} & \multicolumn{3}{c|}{$\begin{array}{c}(0,050-0,075) \\
\text { (Orta) }\end{array}$} & \multicolumn{3}{c|}{$\begin{array}{c}(0,076-0,01) \\
\text { (Büyük) }\end{array}$} \\
\cline { 2 - 12 } & 0.31 & 20.88 & 2.54 & 0.64 & 1.27 & & 4.43 & 5.28 & \\
\cline { 2 - 11 } & 0.46 & 5.51 & & & & & & & \\
\hline
\end{tabular}

Tablo 13. sonuçları irdelendiğinde;

* Pürüzlülüğe bağlı irdeleme: Ortalama değerler göz önüne alındığında HOK'un 3.34 değeri ile küçük pürüzlü akarsularda en düşük, 5.02 değeri ile büyük pürüzlü akarsularda daha büyük ve 8.72 değeri ile orta pürüzlü akarsularda HOK'un en büyük olduğu belirlenmiștir.

Tablo 13. Muskingum Yöntemine Göre Pürüzlülüğe Bağlı HOK Analizi

\begin{tabular}{|c|c|c|c|c|c|c|c|c|c|}
\hline \multirow{4}{*}{$\mathrm{n}$ (Pürüzlülük) } & \multicolumn{3}{|c|}{$\begin{array}{c}\text { (0,025-0,049) } \\
\text { (Küçük ) }\end{array}$} & \multicolumn{3}{c|}{$\begin{array}{c}(0,050-0,075) \\
\text { (Orta) }\end{array}$} & \multicolumn{3}{c|}{$\begin{array}{c}(0,076-0,01) \\
\text { (Büyük) }\end{array}$} \\
\cline { 2 - 11 } & 0.41 & 24.35 & 3.97 & 0.72 & 1.40 & & 5.97 & 6.07 & \\
\cline { 2 - 11 } & 0.60 & 9.45 & & & & & & & \\
\hline
\end{tabular}

Tablo 14. sonuçları irdelendiğinde aşağıdaki tespitler yapılmıştır:

* Pürüzlülüğe bağlı irdeleme: Ortalama değerler göz önüne alındığında R²'nin 0.90 değeri ile orta pürüzlü akarsuda en düşük, 0.91 değeri ile büyük pürüzlü akarsuda daha büyük ve 0.92 değeri ile küçük pürüzlü akarsularda $\mathrm{R}^{2}$ 'nin en büyük olduğu belirlenmiştir.

Tablo 14. Muskingum Yöntemine Göre Pürüzlülüğe Bağlı R² Analizi

\begin{tabular}{|c|c|c|c|c|c|c|c|c|c|}
\hline \multirow{4}{*}{$\mathrm{n}$ (Pürüzlülük) } & \multicolumn{3}{|c|}{$\begin{array}{c}(0,025-0,049) \\
(\text { Küçük ) }\end{array}$} & \multicolumn{3}{c|}{$\begin{array}{c}(0,050-0,075) \\
\text { (Orta) }\end{array}$} & \multicolumn{3}{c|}{$\begin{array}{c}(0,076-0,01) \\
\text { (Büyük) }\end{array}$} \\
\cline { 2 - 11 } & 0.95 & 0.81 & 0.81 & 0.86 & 0.94 & & 0.98 & 0.98 & \\
\cline { 2 - 10 } & 0.88 & 0.95 & & & & & & & \\
\hline
\end{tabular}




\subsection{Genel İrdeleme}

\subsubsection{Muskingum Yöntemine Göre Değişim}

Muskingum Yöntemi ile yapılmış olan tüm hesaplamalar sonucunda elde edilen pürüzlülüğe bağlı OMH, HOK ve $\mathrm{R}^{2}$ değerlerinin değişimi Tablo 15 'de gösterilmiştir.

Tablo 15. Muskingum Yöntemi n Parametresine Göre Genel Hata Analiz Tablosu

\begin{tabular}{|c|c|c|c|}
\hline Muskingum & OMH & HOK & R$^{2}$ \\
\hline n (Pürüzlülük) & $\longleftrightarrow$ & $\longleftrightarrow$ & $\longleftrightarrow$ \\
\hline
\end{tabular}

Muskingum Yöntemi ile yapılan hesaplamalarda n arttığı zaman OMH, HOK ve $\mathrm{R}^{2}$ değerlerinin değişmediği belirlenmiștir.

Pürüzlülüğe bağlı yapılan literatür çalışması ve karşılaştırma sonucunda;

$\checkmark$ Shultz (1992), eğimin 0.0001'den büyük olduğu ve Manning Sürtünme Katsayısının (n) katsayısının 0.03 - 0.01 arasındaki tüm değerlerde Muskingum Yöntemi'nin kullanılabileceği ve iyi sonuçlar verdiğini belirtmiştir.

$\checkmark$ Yapılan ötelenme çalışmasında ele alınan bölgelerin pürüzlülük katsayıları 0.035-0.096 arasındadır. Tablo 15 'de ise Muskingum Yöntemi pürüzlülük katsayısı arttıkça etkilenmediği görülmektedir. Bu nedenle yüksek pürüzlülük katsayılı akarsularda Muskingum Yönteminin kullanılabileceği, bu yönüyle de Shultz'un (1992) çalışmasıyla örtüşmektedir.

\section{SONUÇLAR}

Ülkemizde meydana gelen taşkınlar hem can hem de mal kaybına sebep olmakta, bu da ülkemiz ekonomisini olumsuz yönde etkilemektedir. Bu çalıșmanın amacı, bir taşkın afeti esnasında taşkının meydana geldiği yerdeki taşkın hidrografı kullanılarak, bu noktanın kilometrelerce mansabındaki bir yerdeki taşkın hidrografının saatlerce hatta günlerce önce tahmin edilmesidir.

Konu ile ilgili kapsamlı bir araştırma yapmak için, çalışma alanı olarak önce Türkiye'nin bütün bölgeleri incelenmek istenmiş fakat aynı akarsu üzerinde Akım Gözlem İstasyonu sayısı genelde ikiden az olduğu için ancak 8 havza ve 18 AGİ belirlenmiştir.

Akarsu pürüzlülük katsayısının 0.035 'den 0.096'ya kadar artan değerlerinin ötelenme yöntemleri üzerindeki etkileri incelendiğinde pürüzlülük katsayısının artmasının Muskingum Yönteminin performansında etkin olmadığı belirlenmiştir.

\section{KAYNAKLAR}

Afzali S. H., 2016. Variable-Parameter Muskingum Model, Iranian Journal of Science and Technology, Transactions of Civil Engineering, 40, 1, 59-68.

Akbari, G. ve Firoozi, B., 2010. Implicit and Explicit Numerical Solution of Saint-Venant Equations for Simulating Flood Wave in Natural Rivers, 5th National Congress on Civil Engineering, Ferdowsi University of Mashhad, Mashhad, Iran. 
Muskingum Yönteminin Sürtünme Katsayısına (n) Bağlı Performans Analizi

Al-Humoud, J. ve Esen, İ., 2006. Approximate Methods for the Estimation of Muskingum Flood Routing Parameters, Water Resources Management, 20, 6, 979-990.

Atalay, O., 2008. Taşkın Hidrografının Elde Edilmesiyle İlgili Yöntemlerin Karşılaştırılması, Yüksek Lisans Tezi, KÜ Fen Bilimler Enstitüsü, İnşaat Mühendisliği Anabilim Dalı, Kocaeli.

Balamurugan, M. ve Bhallamudi, S. M., 2017. Flood Routing in an Ephemeral Channel with Compound Cross-Section, Sādhanā, 41, 771-785.

Bayazıt, M. ve Önöz B., 2008. Taşkın ve Kuraklık Hidrolojisi, Nobel Akademik Yayıncılık, Ankara.

Chagas, P. ve Souza, R., 2005. Development of a Numeric Model, with Explicit Solution to Study Flood Wave Propagation, AGU Hydrology Days, Colorado State University, pp. 205-210, Fort Collins, Colorado, USA.

Chaudhry, H. M., 2008. Open-Channel Flow Second Edition, Springer Science Business Media, LLC, 324.S, USA.

Chow, V. T., 1959. Open Channel Hydraulics, McGraw-Hill International Book Company, Inc, New York.

Durmuș, Ș. E., 1997. Değișken Kesitli Akarsu Yataklarında Tașkın Dalga Yayılımının Deterministik Bir Modelle İncelenmesi, Yüksek Lisans Tezi, SDÜ Fen Bilimler Enstitüsü, İnşaat Mühendisliği Anabilim Dalı, Isparta.

Elbashir, S. T., 2011. Flood Routing in Natural Channels Using Muskingum Methods, Master Theses, Dublin Institute of Technology.

Gasiorowski, D. ve Szymkiewicz, R., 2007. Mass and Momentum Conservation in the Simplified Flood Routing Models, Journal of Hydrology, Vol. 346, pp. 51-58.

Gill, M. A., 1978. Flood Routing by The Muskingum Method. Journal of Hydrology, Vol. 36, pp. 353-363.

Haktanir, T. ve Özmen, H., 1997. Comparison of Hydraulic and Hydrologic Routing on Three Long Reservoirs, Journal of Hydraulic Engineering, 123, 2, 153-156.

Keskin, M. E., 1989. Farklı Enkesitli Akarsularda Kinematik Modelle Taşkın Ötelemesi, Yüksek Lisans Tezi, İTÜ Fen Bilimler Enstitüsü, İnşaat Mühendisliği Anabilim Dalı, İstanbul.

Keskin, M. E., 1994. Tașkın Dalgasının Bağımlı Değișken Parametreli Dinamik bir Modelle İncelenmesi, Doktora Tezi, İTÜ Fen Bilimler Enstitüsü, İnșaat Mühendisliği Anabilim Dalı, İstanbul.

Kshirsagar, M. M., Rajagopalan, B. ve Lal, U., 1995. Optimal Parameter Estimation for Muskingum Routing with Ungauged Lateral Inflow, Journal of Hydrology, 169, 1-4, 25-35.

Kundzewicz Z. W. ve Strupczewski W. G., 1982. Approximate Translation in the Muskingum Model, Hydrological Sciences Journal, 27, 1, 19-17.

Maidment, D. R., 1993. Handbook of Hydrology, McGraw-Hill, Inc. 10,1.

Niazkar M. ve Afzali H.S, 2017. New Nonlinear Variable-parameter Muskingum Models, KSCE Journal of Civil Engineering, 21(7), 2958-2967

Özdoğan, İ., 2010. Akarsularda Tașkın Öteleme Modelleri: Alara Çayı Uygulaması Doktora Tezi SDÜ Fen Bilimler Enstitüsü, İnşaat Mühendisliği Anabilim Dalı, Isparta.

Singh, V. P., 2004. Flow Routing in Open Channels: Some Recent Advances, Second International Conference on Fluvial Hydraulics, University of Napoli Federico II, Naples, 23 p., Italy. 
Afet ve Risk Dergisi Cilt: 2 Sayı: 2, 2019 (115-127)

Metin SARIGÖL

Soentoro, E. A., 1991. Comparision of Flood Routing Methods. Master Theses, University of British

Columbia, Vancouver, Canada.

Stephenson, D. 1979. Direct Optimization of Muskingum Routing Coefficients: An Extension to the Paper By Gill, MA, 1978. Flood Routing By The Muskingum Method. J. Hydrol., 36: 353-363, Journal of Hydrology, $41,1-2,161-165$.

Shultz, M. J., 1992. Comparison of Flood Routing Methods for Rapidly Rising Hydrograph Routed Through a very Wide Channel, Master Thesis, The University of Texas, Arlington.

Tung, Y. K., 1985. River Flood Routing by Nonlinear Muskingum Method, Journal of Hydraulic Engineering, $111,12,1447-1460$.

Ülke, A., 2001. Taşkın Öteleme Metodları, Seminer I Notları, Isparta.

Ülke, A., 2003. Muskingum Metodu Kullanılarak Taşkın Ötelenmesi, Yüksek Lisans Tezi, SDÜ Fen Bilimler Enstitüsü, İnşaat Mühendisliği Anabilim Dalı, Isparta.

Ülke, A. ve Kaya, B., 2012. Kinematik Dalga Modelinin DQM ile Çözümü ve Sütçüler Taşkını Örneği, 58695884, Yazı 374, İMO Teknik Dergi.

URL 1, Coğrafya Harita, http://cografyaharita.com/haritalarim/2eturkiye-akarsu-havzalari-haritasi.png, (Son Erişim: 12.Şubat.2018).

URL 2, Devlet Su İşleri, http://rasatlar.dsi.gov.tr/, (Son Erişim: 04.Ekim.2017). 